\title{
Futbol Hakemlerinin Farklı Egzersiz Şiddetlerinde Sezinleme Zamanı, Kan Laktat Düzeyi ve Karar Verme Becerilerinin İncelenmesi*
}

\section{Examining the Coinciding-Anticipation Timing, Blood Lactate Level and Decision- Making of Football Referee at Different Exercise Intensities}

ORİJINAL ARASSTIRMA/
ORIGINAL RESEARCH

\section{Kurtuluş ASLAN ${ }^{1 \dagger}$ \\ Özcan SAYGIN ${ }^{2}$}

Halil İbrahim CEYLAN ${ }^{3}$

${ }^{1}$ Muğla Sitk1 Koçman Üniversitesi https://orcid.org/0000-0001-7879-9180

${ }^{2}$ Muğla Sitk1 Koçman Üniversitesi https://orcid.org/0000-0003-0380$586 \mathrm{X}$

${ }^{3}$ Muğla Sitkı Koçman Üniversitesi https://orcid.org/0000-0003-1133-5511

\section{Yayın Bilgisi}

Gönderi Tarihi: 12.10 .2018

Kabul Tarihi: 16.12.2018

Online Yayın Tarihi: 31.12.2018

\section{Öz}

Bu çalışma, futbol hakemlerinin farklı egzersiz şiddetlerinde sezinleme zamanı, kan laktat düzeyi ve karar verme becerilerini incelemek amacıyla yapılmıştır. Çalışmaya Muğla ilinde hakemlik yapan, herhangi bir sağlık problemi ve sportif yaralanması olmayan 12 erkek futbol hakemi (yardımcı hakem: 6, hakem: 6) gönüllü olarak katılmıştır. Çalışmaya katılan hakemlere, farklı günlerde bisiklet ergometresinde düşük şiddetli $(\% 40)$ egzersiz, orta şiddetli (\%60) egzersiz, yüksek şiddetli (\%90) egzersiz protokolü uygulanmıştır. Hakemlerin her bir egzersiz şiddeti için belirlenen hedef kalp atım sayısında sezinleme zamanı ve maç içerisinde çok sık rastlanan pozisyonlarla ilgili karar verme becerileri egzersiz sırasında ölçülmüsşür. Ayrıca hakemlerin her bir egzersiz öncesi ve egzersiz sonrasında (1., 4. ve 8. dk) kan laktat düzeyi incelenmiştir. İstatiksel analiz sonucunda; düşük, orta ve yüksek egzersiz şiddeti sırasında ölçülen mutlak hata skorları (6mph ve $12 \mathrm{mph})$ karşılaştırıldığında, istatiksel olarak anlamlı farklılık bulunmamıştır ( $p>0.05)$. Düşük, orta ve yüksek şiddetteki egzersizler sırasında ölçülen karar verme becerilerinin karşılaştırılmasında istatiksel olarak anlamlı fark bulunmuştur $(\mathrm{p}<0.05)$. Her üç egzersiz şiddetinde de (düşük, orta, yüksek) egzersizden önce, egzersizden sonra 1. dakika, 4. dakika ve 8. dakikada ölçülen kan laktat düzeyinin karşılaştırılmasında istatiksel olarak anlamlı fark görülmüştür $(p<0.05)$. Düşük şiddetteki egzersizden sonra 8 . dakikada ölçülen kan laktat düzeyi ile karar verme toplam skoru arasında istatiksel olarak negatif yönde ilişki bulunmuştur $(\mathrm{r}=.-577, \mathrm{p}<0.05)$. Yüksek egzersiz şiddeti sırasında ölçülen mutlak hata skoru (6mph) ile egzersizden sonra 4. dakika $(r=.662, \mathrm{p}<0.05)$ ve 8 . dakikada $(r=.741, p<0.05)$ ölçülen kan laktat düzeyi değerleri arasında anlamlı ilișki bulunmuştur. Hakemlerin antrenman programlarının planlanmasında fiziksel ve fizyolojik özelliklerinin yanı sıra bilişsel fonksiyonlarının da yorgunluğa olan toleransını geliştirici egzersizlerin programa dahil edilmesinin önemli olduğu düşünülmektedir.

Anahtar Kelimeler: Futbol Hakemi, Karar Verme, Sezinleme Zamanı, Kan Laktat Düzeyi.

\begin{abstract}
The study was conducted to examine the coinciding anticipation timing, blood lactate level and decision-making of football referees at different exercise intensities. Twelve male referees (6 referees and 6 asistant referees) who were all active in Mugla and had any health problems and injuries, participated in this study voluntarily. Low intensity exercise (\%40), moderate intensity exercise (\%60) and high intensity exercise (\%90) were applied to the referees on the cycling ergometer on different days. The referees' coinciding anticipation timing and decision-making skills about positions that occur very often in the match were measured at the target heart rate determined for each exercise intensity. In addition, blood lactate levels of referee were also examined before each exercise protocol and after exercise (1., 4 and 8 . min). As a result of the statistical analysis, when the absolute error scores (6mph and $12 \mathrm{mph}$ ) measured during the low, moderate and high exercise intensity were compared, no statistically significant difference was found ( $p>0.05$ ). In the comparison of measured decision-making skills during the low, moderate and high intensity exercise were found to be significant. A statistically significant difference was observed in the comparison of the blood lactate levels measured rest (before exercise), the 1st minute, 4th minute and 8th minute after exercise at all three exercise intensity (low, moderate, high). A statistically significant negative correlation was found between the blood lactate level measured at 8th minute after the low intensity exercise and total score of decision-making $(r=.-577, p<0.05)$. Significant positive correlation were found between absolute error $(6 \mathrm{mph})$ measured high exercise intensity and blood lactate levels measured at 4 th minute $(r=.662, p<0.05)$ and 8 th minute $(r=.741, p<0.05)$ after high intensity exercise. In the planning of training programmes of the referees, , it is thought to be important to add the cognitive functions to the training programmes for the improving tolerance of exhaustion as well as the physical and physiological function.
\end{abstract}

Keywords: Football Referee, Decision-making, Coinciding Anticipation Timing, Blood Lactate Level. Lactate I

\footnotetext{
* Bu çalışma, 5 - 8 Nisan 2018 tarihleri arasında Alanya'da düzenlenen Uluslararası Herkes için Spor ve Welness Kongresinde sözel bildiri olarak sunulmuştur.

† Sorumlu yazar: Kurtuluş Aslan, kurtulusaslan2@gmail.com
} 


\section{GİRIŞ̧}

Hakemler futbol oyununun temel unsurlarından bir tanesidir. Hakemin görevi oyunun rekabet gücünü olumsuz yönde etkilemeden kuralları doğru ve tutarlı bir şekilde uygulamaktır (Gaoua ve ark., 2017). Topun hızı ve yönünün sürekli değişmesinden dolayı hakemler de yoğunluğu değişen ve sürekli olmayan aktiviteler yapar. $\mathrm{Bu}$ nedenle maç sırasında pek çok fizyolojik zorlanmaya maruz kalır. Hakemler 90 dakika boyunca ortalama kalp atım hızının \%85'ine ulaşmakta, bu da egzersiz şiddetinin anaerobik eşik düzeyine yaklaştığını göstermektedir (Helsen ve Bultynck, 2004). Resmi maçlarda hakemlerin 9-13 km mesafe koştuğu, bunun yaklaşık \%4 ile \%18'inin yüksek şiddette egzersiz olduğu, kan laktat düzeyinin ise 14 mmol'a kadar yükseldiği görülmüştür (Castagna ve ark., 2007). Elit futbol hakemlerinin maç içerisindeki fiziksel performansı futbol oyuncularınınki kadar iyi olması gerekir (Weston ve ark., 2011). Futbol hakemlerinin fiziksel performansları, doğru karar verme yetenekleriyle ayrılmaz bir şekilde bağlantılıdır; bu nedenle karar verme, hakemliğin önemli bir yönüdür (Weston, 2015). Bir hakemin karar vermesi hareketin oluştuğu anda veya mümkün olan en kısa sürede olmalıdır (Ekmekçi, 2011). Literatüre bakıldığında doğru karar vermenin, hakemlerin iyi bir fiziksel kapasite ve fiziksel uygunluk unsurlara sahip olması (Riiser ve ark., 2017; Schenk ve ark., 2018), oyun alanında doğru konumlanması (Mallo ve ark., 2012; Schenk ve ark., 2018) ile yüksek düzeyde ilişkili olduğu belirtilmiştir. Hakemler, oyunun hızına ayak uydurmalı ve oyuncuların kurallara uyup uymadıklarını belirlemek için doğru pozisyon alarak oyunu yakından takip etmelidir (Schenk ve ark., 2018). Yapılan bir çalışmada, hakemlerin pozisyonları 11-15 m mesafeden takip ettiğinde yanlış karar verme riskinin azaldığı belirtilmiştir (Mallo ve ark., 2012). Hakemlerin fiziksel ve fizyolojik açıdan belirli yeterliğe sahip olması karar verme düzeyini etkilediği gibi, karar verme becerisi hakemin sahip olduğu algısal ve bilişsel özelliklerden de etkilenebilir. Literatüre bakıldığında üst düzey performans ile ilişkili, bir dizi alana özgü algısal-bilişsel beceriler tanımlanmıştır (Spitz ve ark., 2018). Bu algısal ve bilişsel becerilerden bir tanesi de sezinleme zamanıdır.

Sezinleme zamanı olayın kendisinden önce gerçekleşmesi muhtemel olanı tahmin etme yeteneğini ifade eder (Piras ve ark., 2014). Sezinleme zamanının doğru oyuncunun uyaran ile hedefin zaman ve konum özellikleri hakkında bilgi edindiği duyusal bir aşama, hareket cevabının duyusal bilgilerle bütünleştiği bir sensorimotor aşama ve hareketin yürütüldüğü 3 aşamalı bir süreç olarak ifade edilmektedir (Williams, 2000). Oyun okuma yeteneği olarak da tanımlanan sezinleme zamanı, bir rakibin eyleminden önce genellikle kararların alınması gereken hızlı oyunlu sporlarda oldukça önemlidir (Piras ve ark., 2014). Ne olacağının önceden kestirilmesi, uygun cevap vermek için zaman yaratılmasına olanak sağlar (Spitz ve ark., 2018). Özellikle, topla oynanan oyunlarda olayların önceden tahmin edilmesinde, top ile ilgili tüm bilgilerin alınması (Sors ve ark., 2017) ile rakibin vücut hareketlerinden postüral ipuçlarını alma önemlidir (North ve ark., 2016). Hakemlerin iyi bir sezinleme zamanına sahip olması, 
oyun alanı içinde doğru pozisyon almasına yardımcı olur. Böylece, hakem herhangi bir karar öncesi iyi yer alarak karar verme doğruluğunu artırır (Byun ve ark., 2014; Elsworthy ve ark., 2014).

Sezinleme zamanı ve karar verme becerisi yüksek şiddette yapılan egzersizlerden olumsuz etkilenmektedir (Duncan ve ark., 2014; Elsworthy ve ark., 2014). Yapılan çalışmalarda anaerobik laktat eşik noktasına yakın düzeyde yapılan egzersizin bilişsel performans üzerinde olumsuz etki yaratmadığ (Hüttermann ve Memmert, 2018), hatta geliştirdiği görülmüştür (Riquelme, 2015; Mcmorris ve Hale, 2015). Literatürde akut egzersiz ile bilişsel performans arasındaki ilişkiye bakıldığında farklı sonuçlar görülmektedir. Bazı çalışmalarda şiddetli egzersizin bilişsel performansı olumsuz yönde etkilediği (Hüttermann ve ark., 2014; Smith ve ark., 2016; Almonroeder ve ark., 2018; Ceylan ve Saygin, 2018), bazı çalışmalarda herhangi bir etkiye sebep olmadığı (Davrance ve ark., 2015; Lyons ve ark., 2008) görülmüştür. Egzersiz ile bilişsel performans arasındaki ilişkinin sonuçları çeşitli teorilere dayandırılmıştır. Bu teoriler Ters U hipotezi, Catastrophe Modeli (Jarvis, 2006) ile bireysel optimal işlevsel bölge (IZOF) teorisidir (Robbins ve Madrigal, 2016).

Müsabaka veya yarışma ortamı, hızlı bilişsel süreçleri gerektirir. Sporcular, algısal ve bilişsel performanslarını yorgunken bile üst noktada tutmak zorundadır. Bu yüzden, sporcuların temel bilişsel işlem becerilerinin belirlenmesinin yanı sıra, yorgunluğun bilişsel işlem kapasitesini nasıl etkilediğini, bununda hareket kontrolüne nasıl yansıyacağını anlamak da önemlidir. Dinamik spor ortamında, sporcuların hareketlerini yönlendirebilmesi için görsel bilgiyi sınırlı zaman içerisinde kullanması gerekir $\mathrm{Bu}$ da etkili bilişsel işlem sürecini gerektirir. (Almonroeder ve ark., 2018). Aynı şey bir futbol hakemi içinde geçerlidir. Futbol hakemi maç içerisinde aralıklı olarak yüksek şiddette aktivite yapmaktadır (Da Silva ve ark., 2008). Yorgunken bile kısa zaman içerisinde, oyunu iyi okuyup doğru karar vermesi önemlidir. Literatürde futbol hakemlerinin maç içerisindeki performanslarının ölçülmesi ile ilgili çalışmalar mevcuttur (D'Ottavio ve Castagna, 2001; Da Silva ve ark., 2008; Krustrup ve ark., 2002; Krustrup ve ark., 2009; Weston, Drust, Atkinson ve Gregson, 2011; Castillo ve ark., 2018; Choi ve Roh, 2018). Laboratuvar ortamında futbol hakemlerinin farklı egzersiz şiddetlerinde sezinleme zamanı ve karar verme becerilerini inceleyen ve bu algısal-bilişsel özellikler ile kan laktat düzeyi arasındaki ilişkiyi ortaya koyan çalı̧̧malar sınırlıdır. Bu da çalışmanın önemini ortaya koymaktadır. 


\section{YÖNTEM}

\section{Örneklem grubunun belirlenmesi}

Örneklem grubunun belirlenmesinde, ilk olarak Türkiye Futbol Federasyonu Muğla İl Hakem Kurulu'ndan izin alınarak faal olarak hakemlik yapan bireyler ile yüz yüze görüşüldü. Görüşmede, çalışmanın amacı ve içeriği hakkında bilgi verilerek, çalışmaya katılmak isteyen gönüllü bireyler belirlendi. Daha sonra, çalışmaya katılmayı kabul eden gönüllülere Bilgilendirilmiş Olur Formu imzalatılarak, 1.oturuma çağrıldı.

\section{Katılımcilar ve Etik Onay}

Bu çalışmaya, Muğla ilinde faal olarak hakemlik yapan 12 erkek futbol hakemi (yardımcı hakem: 6, hakem: 6) gönüllü olarak katıldı. Çalışmaya başlamadan önce M.S.K.Ü Sağlık Bilimleri Etik Kurulu'ndan izin alındı (Karar no: 18, Protokol no: 18).

\section{Deneysel Prosedür}

Çalışmanın ölçümleri sabah 08.00-12.00 saatleri arasında, 4 oturumda gerçekleştirildi. 1. oturumda hakemler, M.S.K.Ü. Spor Bilimleri Fakültesi Laboratuvarı'na davet edilerek çalışmanın yöntemsel modeli ve sezinleme zamanı ölçüm cihazı (Bassin Anticipation Timer) hakkında bilgilendirildi. Daha sonra, hakemlerin boy uzunluğu ve vücut ağırlığı ölçümleri yapıldı. Hakemler, 2. oturumda \%40, 3. oturumda $\% 60,4$. oturumda \%90 egzersiz şiddetinde bisiklet ergometresinde egzersize tabi tutuldu. Her bir oturum günü arasında hakemlere 2 gün dinlenme verildi. 2., 3., 4. oturumdan önce hakemler, ağır egzersiz yapmamaları ve kafein tarzı uyarıcı madde almamaları konusunda bilgilendirildi. Egzersize hafif kahvaltı yaparak gelmeleri istendi.

Laboratuvarda her bir hakemin farklı egzersiz şiddetlerinde (2., 3., 4. oturum) sezinleme zamanı, kan laktat düzeyi ve kara verme becerilerini incelemek için hakemler laboratuvara tek tek çağrıldı ve aşağıda belirtilen deneysel prosedür sırası kullanıldı;

Hakeme ilk olarak polar saat takılarak sırasıyla dinlenik kalp atım sayısı ve dinlenik kan laktat düzeyi belirlendi. Daha sonra, Karvonen yöntemi ile belirlenen egzersiz şiddeti için hedef kalp atım sayısı hesaplandı. Daha sonra hakem, 8-10 dakika arasında Monark Ergomediks 834 (Ergomedic, Finland) marka bisiklet ergometresinde pedal yükü olmadan ısındı. Isınma bölümünden sonra, hakeme bisiklet ergometresinde (başlangıç pedal yükü: $1 \mathrm{~kg}$, steady-state durumuna gelene kadar her $30 \mathrm{sn}$ de $0.5 \mathrm{~kg}$ pedal yükü artırılarak) (Duncan ve ark., 2013) pedal çevirmesi istendi. Hakem, hesaplanan hedef kalp atım sayısına geldiğinde ilk olarak sezinleme zamanı ölçümü gerçekleştirildi. Her bir uyarı hızı için (6mph ve $12 \mathrm{mph}) 5$ olmak üzere toplamda 10 ölçüm randomsal olarak yapıldı. Sezinleme zamanı ölçümlerinin akabinde maç içerisinde sık rastlanan pozisyonlarla ile ilgili 15 saniyelik toplam 20 video 
hakemlere izletilerek, karar vermesi istendi. Sezinleme ve karar verme becerilerinin ölçümünden sonra, egzersiz sonlandırıldı. Tekus ve ark., (2012)'nın yaptıkları çalışmada belirtildiği gibi hakemlerin, egzersiz bittikten sonra 1., 4., 8., dakika da kan laktat düzeyleri ölçüldü (Şekil 1).

*Hakemlerin steady-state durumuna geliş süresi, egzersiz şiddetine ve kondisyon düzeyine göre ortalama 4 ile 8 dakika arasında sürdü. Hakemler hesaplanan hedef kalp atım sayısına geldikten sonra, sezinleme zamanı ölçümleri için 2 dakika, karar verme becerilerinin ölçümü için (15 sn'lik 20 video) 5 dakika olmak üzere toplamda 7 dakika daha egzersizi sürdürdü. Her bir egzersiz oturumunda hakemlere aynı videolar izletildi fakat yerleri değiştirildi. Ayrıca hakemler sezinleme zamanı ölçümleri yapılırken uyarı hızları, egzersiz şiddetleri hakkında ve karar verme için kullanılan videolar hakkında önceden bilgilendirilmedi. Çalışmanın ölçümleri 10 gün içerisinde tamamlandı.

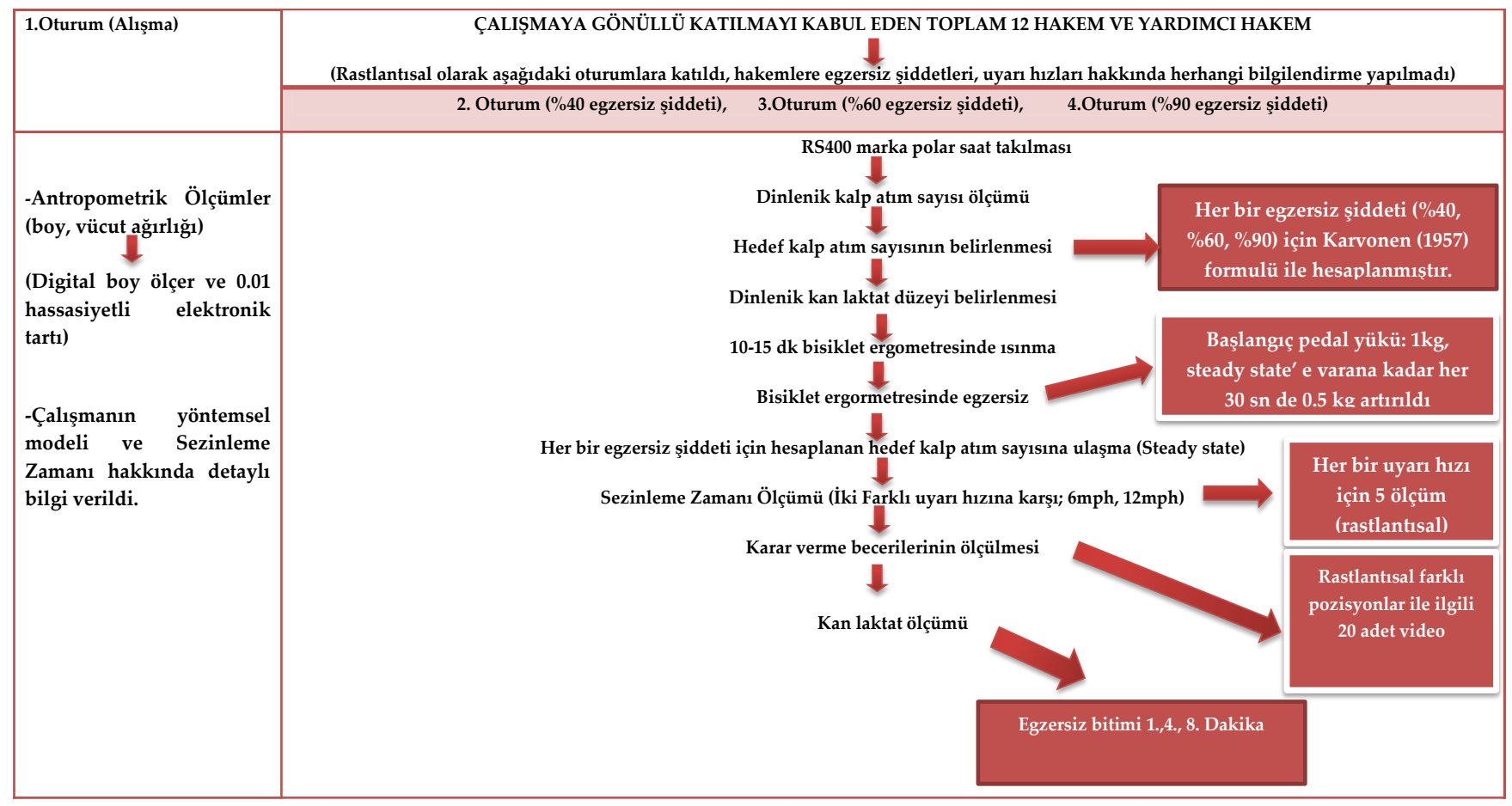

${ }^{*}$ Her oturum farklı günlerde, oturumlar arası 2 gün dinlenme, Egzersiz şiddetleri için ACSM (2014) kriter alındı.

Şekil 1. Hakemlere uygulanan deneysel prosedür

\section{Veri toplama araçları:}

Vücut Ağırlığı ve Boy Uzunluğu: Ağırlık 0.1 kg hassaslıkta bir elektronik terazi ile ölçülürken, boy $0.01 \mathrm{~cm}$ hassaslıkta dijital boy ölçer aletiyle ölçüldü (Günay ve ark., 2013).

Kalp Atım Hızı: Katılımcıların, farklı şiddetlerdeki egzersizler sırasındaki kalp atım hızları, göğsüne yerleştirilen bir verici ve kolunda takılı olan telemetrik monitörler (Polar RS400, Finland) aracılığ 1 ile takip edildi. 
Egzersiz Şiddetinin Belirlenmesi: Araştırmaya katılan hakemlerin egzersiz şiddeti Karvonen Metodu ile belirlendi (Karvonen ve ark, 1957).

Kan Laktat Analizi: Kan laktat ölçümü; dinlenme, egzersiz bitiminden sonra 1.dakika, 4. dakika ve 8. dakika olmak üzere Nova Biomedical Lactate Plus 40828 marka laktat ölçer aleti ile katılımcıların parmak ucundan alındı (Tekus ve ark., 2012).

Sezinleme Zamanı Ölçümü: Hakemlerin farklı egzersiz şiddetleri için (\%40, \%60, \%90) hesaplanan hedef kalp atım sayısında (Ferguson, 2014) farklı uyarı hızlarındaki (6mph, $12 \mathrm{mph}$ ) sezinleme zamanı ölçümü bisiklet ergometresi önüne yerleştirilen Bassin Anticipation Timer aleti ile yapıldı (Rudisill ve Jackson, 1992’ den aktaran Sögüt ve ark., 2009). Cihaz, kontrol konsolü ve cevap verme butonu ile LED ışıklarının (49 lamba) doğrusal bir seri şeklinde hareket ettiği runway (set; LED 1şıklarının hareket ettiği zemin) olarak adlandırılan 3 parçadan oluşur. Tüm LED 1şıklar, doğrusal bir düzende sıralanmış, katılımcılara doğru hareketli uyaran (soldan sağa doğru) geliyor mantığıyla dizayn edilmiştir (Alaei, 2015). Bu çalışmada, tüm denemelerde, başlangıç ve bitiş hızları her bir farklı uyarı hızı için 6, 12mph şeklinde sabitlenmiş ve hedef 1 şık, 3. setin son 1şı̆̆ı olarak seçildi. Hakemlerin, denemenin zamanını tahmin etme konusundaki olasılığını en aza indirmek için, aletin uyarı 1şığı, 1 saniye bir minimum gecikme ve 2 saniyelik maksimum gecikme şeklinde rastgele ayarlandı (Duncan ve ark., 2013). Hakem, her bir egzersiz şiddeti için hesaplanan hedef kalp atım sayısına geldiğinde her bir uyarı hızında (6mph, 12mph) 5 olmak üzere toplamda 10 ölçüm randomsal olarak alındı. Ölçümler milisaniye cinsinden tepkinin geç veya erken olması şeklinde kaydedildi. Milisaniye cinsinden alınan ölçümler, mutlak hata skoruna dönüştürülerek, istatiksel analiz için değerlendirmeye alındı (Rudisill ve Jackson, 1992’ den aktaran Söğüt ve ark., 2009).

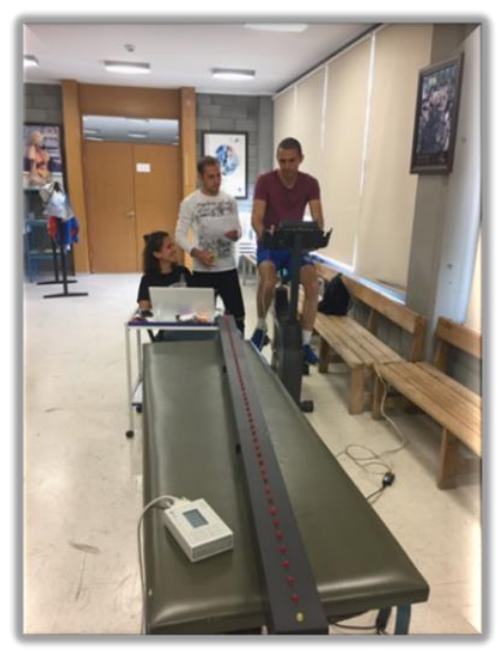

Şekil 2. Bisiklet ergometresinde farklı egzersiz şiddetlerinde sezinleme zamanı ve karar verme becerisi ölçümü 
Karar Verme Becerisi: Literatüre bakıldığında video analizi ile hakemlerin karar verme becerilerini ölçen çalışmalar mevcuttur (Kittel ve ark., 2018; Spitz ve ark., 2018). Bu çalışmada, hakemlerin farklı egzersiz şiddetlerinde karar verme becerilerinin belirlenmesinde Türkiye Futbol Federasyonu'nun hakemlere aylık olarak yaptığı eğitimlerde kullandığı videolardan yararlanıldı. Hakemlere, steady state durumunda ve sezinleme zamanı ölçümlerinin tamamlanmasından sonra farklı pozisyonları içeren (teknik ceza için; 15 tane direk serbest vuruş ( 2 tanesi penaltı), 3 tane endirek serbest (2 tanesi ofsayt), 2 tane oyuna devam seçeneği, disiplin yaptırımı için; 7 tane ihtar, 8 ihraç, 5 tane de kart yok seçeneği) toplam 20 adet 15'er saniyelik maç videosu izletilerek, pozisyonlar hakkında anında karar vermesi istendi. Videolarda doğru cevap seçeneği için teknik cezayı belirleme 1 puan, disiplin yaptırımlarını belirleme 1 puan olacak şekilde her bir video testi için toplam 2 puan ve tüm test için toplamda maksimum 40 puanlık puanlama sitemi oluşturuldu.

\section{İstatistiksel Analiz}

Araştırmada elde edilen tüm veriler, SPSS (version 16.0) programında kaydedildi. Shapiro Wilk test sonuçlarına göre her bir değişken için p değeri 0.05 'ten büyük olarak bulundu. Hakemlerin farklı egzersiz şiddetlerinde sezinleme zamanı ve karar verme becerisi ile kan laktat düzeyi arasındaki farklılıkları bulmak için Tekrarlı Ölçümlerde Varyans Analizi, ikili karşılaştırmaların olduğu durumlarda ise Bonferroni Testi kullanıldı. Küresellik, Mauchly testi ile analiz edildi. Sphericity Assumed değerleri dikkate alındı. Sezinleme zamanı ve karar verme becerisi ile kan laktat düzeyi arasındaki ilişkiyi incelemek için Pearson Correlation testi kullanıldı. Anlamlılık düzeyi $\mathrm{p}<0.05$ olarak kabul edildi.

\section{BULGULAR}

Tablo 1. Hakemlerin ve yardımcı hakemlerin yaş, boy uzunluğu, vücut ağırlığı ve deneyimlerini gösteren tablo.

\begin{tabular}{llccc}
\hline & Gruplar & Sayı & $\mathbf{X}$ & S.S. \\
\hline \multirow{2}{*}{ Yaş (yıl) } & Hakem & 6 & 24.00 & .63 \\
& Yardımcı Hakem & 6 & 21.83 & 1.83 \\
Boy (cm) & Hakem & 6 & 183.00 & 7.15 \\
& Yardımcı Hakem & 6 & 180.66 & 7.42 \\
Vücut Ăğırlı̆̆ı (kg) & Hakem & 6 & 77.83 & 4.70 \\
& Yardımcı Hakem & 6 & 72.66 & 7.96 \\
Deneyim (yıl) & Hakem & 6 & 4.33 & .81 \\
& Yardımcı Hakem & 6 & 4.00 & .00 \\
\hline
\end{tabular}

Tablo 1'de gösterildiği gibi, hakemlerin yaş $24.00 \pm .63$ yıl, boy $183.00 \pm 7.15 \mathrm{~cm}$, vücut ağırlığı $77.83 \pm 4.70 \mathrm{~kg}$, deneyimi $4.33 \pm .81 \mathrm{y} 1$, yardımcı hakemlerin ise yaş $21.83 \pm 1.83$ yıl, boy $180.66 \pm 7.42 \mathrm{~cm}$, vücut ağırlığı $72.66 \pm 7.96 \mathrm{~kg}$, deneyimi $4.00 \pm .00$ y1l olarak bulunmuştur. 
Tablo 2. Düşük (\%40), orta $(\% 60)$ ve yüksek (\%90) şiddetteki egzersizler sırasındaki mutlak hata skorlarının (6mph) (ms) karşılaştırılması.

\begin{tabular}{cccccc}
\hline Egzersiz Şiddeti & X & S.S. & Sayı & F & p \\
\hline Düşük (\%40) & 34.8 & 15.06 & 12 & & \\
Orta (\%60) & 48.5 & 22.27 & 12 & 1.454 & .117 \\
Yüksek (\%90) & 42.1 & 27.87 & 12 & & \\
\hline
\end{tabular}

Tablo 2'de gösterildiği gibi Mauchly's testi sonucuna göre, küresellik varsayımı $\mathrm{p}=.235$ olarak bulunmuştur. Dolayısıyla Sphericity assumed değerleri dikkate alınmıştır. Tekrarlı Ölçümlerde Varyans Analizi sonuçlarına göre; \%40, \%60 ve \%90 egzersiz şiddetleri sırasındaki mutlak hata skorları (6mph) karşılaştırıldığında, istatiksel olarak anlamlı farklılık bulunamamıştır $(F(2,22)=1.451, \mathrm{p}=.117)$.

Tablo 3. Düşük (\%40), orta $(\% 60)$ ve yüksek $(\% 90)$ şiddetteki egzersizler sırasındaki mutlak hata skorlarının (12mph) (ms) karşılaştırılması.

\begin{tabular}{cccccc}
\hline Egzersiz Şiddeti & $\mathbf{X}$ & S.S. & Sayı & F & p \\
\hline Düşük (\% 40) & 27.7 & 12.35 & 12 & & \\
Orta (\%60) & 30.8 & 16.95 & 12 & .300 & .744 \\
Yüksek (\%90) & 32.5 & 18.32 & 12 & & \\
\hline
\end{tabular}

Mauchly's testi sonucuna göre, küresellik varsayımı p=.625 olarak bulunmuştur. Tablo 3'de gösterildiği gibi Sphericity assumed değerleri dikkate alınmıştır. Tekrarlı Ölçümlerde Varyans Analizi sonuçlarına göre; \%40, \%60 ve \%90 egzersiz şiddetleri sırasındaki mutlak hata skorları (12mph) karşılaştırıldığında, istatiksel olarak anlamlı farklılığa rastlanılmamıştır $(F(2,22)=.300, p=.744)$.

Tablo 4. Düşük (\%40), orta (\%60) ve yüksek (\%90) şiddetteki egzersizler sırasında ölçülen karar verme becerilerinin toplam skorunun karşılaştırılması.

\begin{tabular}{cccccc}
\hline Egzersiz Şiddeti & $\mathbf{X}$ & S.S. & Sayı & F & p \\
\hline Düşük (\% 40) & 32.16 & 2.72 & 12 & & \\
Orta (\% 60) & 30.58 & 3.77 & 12 & 7.004 & $.004^{*}$ \\
Yüksek (\%90) & 29.08 & 1.78 & 12 & & \\
\hline
\end{tabular}

Mauchly's testi sonucuna göre, küresellik varsayımı p=.069 olarak bulunmuştur. Tekrarlı Ölçümlerde Varyans Analizi sonuçlarına göre; düşük (\%40), orta (\%60) ve yüksek (\%90) şiddetteki egzersiz sırasında ölçülen karar verme becerilerinin karşılaştırılmasında istatiksel olarak anlamlı fark bulunmuştur $(\mathrm{F}(2,22)=7.004, \mathrm{p}=.004)$. Yapılan ikili karşılaştırmalarda, düşük (\%40) ile yüksek (\%90) şiddetteki egzersizler sırasında ölçülen karar verme becerileri arasında anlamlı düzeyde farklılık bulunmuştur (ortalama fark1: 3.083, p=.002). Hakemler, düşük, orta ve yüksek şiddetli egzersizlerde, 
sırasıyla \%80.4, \%76.45, \%72.7’ini doğru karar vermiştir. Hakemlerin, yüksek şiddetli egzersiz sırasında verdikleri kararlar, düşük şiddetli egzersiz sırasında verdikleri kararlar ile karşılaştırıldığında, \%7.7 karar verme performansında azalma gözlemlenmiştir.

Tablo 5. Dinlenik ve düşük (\%40) şiddetteki egzersizden sonra 1. dakika, 4. dakika ve 8. dakikada ölçülen kan laktat düzeylerinin (mmol) karşılaştırılması.

\begin{tabular}{cccccc}
\hline Kan laktat düzeyi & $\mathbf{X}$ & S.S. & Sayı & F & p \\
\hline Dinlenik & 1.85 & 1.18 & 12 & & \\
1.Dakika & 4.51 & 1.64 & 12 & 3.100 & $.040^{*}$ \\
4. Dakika & 3.00 & 1.04 & 12 & & \\
8. Dakika & 3.67 & 4.32 & 12 & & \\
\hline
\end{tabular}

Tablo 5'de görüldüğü gibi dinlenik ve düşük (\%40) şiddetteki egzersizden sonra 1. dakika, 4. dakika ve 8. dakikada ölçülen kan laktat düzeyinin karşılaştırılmasında istatiksel olarak anlamlı fark görülmüştür $(\mathrm{F}(3,33=3.100, \mathrm{p}=.040)$. Bonferroni testi sonuçlarına göre; dinlenik kan laktat değeri ile egzersizden sonra 1. dakikada ölçülen kan laktat düzeyi arasında (ortalama fark: $-2.658^{*}, p=.000$ ); egzersizden sonra 1. dakika ile 4. dakikalarda ölçülen kan laktat düzeyleri arasında (ortalama fark: 1.517*, $\mathrm{p}=.009$ ) istatiksel olarak anlamlı düzeyde farkl1lık bulunmuştur.

Tablo 6. Dinlenik ve Orta (\%60) şiddetteki egzersizden sonra 1. dakika, 4. dakika ve 8 . dakikada ölçülen kan laktat düzeylerinin (mmol) karşılaştırılması.

\begin{tabular}{cccccc}
\hline Kan laktat düzeyi & $\mathbf{X}$ & S.S. & Sayı & F & p \\
\hline Dinlenik & 1.52 & .58 & 12 & & \\
1.Dakika & 5.15 & 1.46 & 12 & 44.181 & $.000^{*}$ \\
4. Dakika & 4.10 & 1.18 & 12 & & \\
8. Dakika & 3.73 & 1.16 & 12 & & \\
\hline
\end{tabular}

Mauchly's testi sonucuna göre, küresellik varsayımı $\mathrm{p}=.631$ olarak bulunmuştur. Tablo 6' da görüldüğü gibi Dinlenik ve orta (\%60) şiddetteki egzersizden sonra 1. dakika, 4. dakika ve 8. Dakikada ölçülen kan laktat düzeylerinin karşılaştırılmasında istatiksel olarak anlamlı düzeyde fark bulunmuştur $(\mathrm{F}(3,33)=44.181, \mathrm{p}=.000)$. Bonferroni testi sonuçlarına göre; dinlenik kan laktat düzeyi ile egzersizden sonra 1. dakika (ortalama fark1: $-3.633, \mathrm{p}=.000$ ), 4. dakika (ortalama fark1: $-2.575, \mathrm{p}=.000$ ) ve 8. dakikada ölçülen kan laktat düzeyi arasında (ortalama farkı: -2.208, p=.000) istatiksel olarak anlamlı fark bulunmuştur. Ayrıca, egzersizden sonra 1. dakika ile 4. dakika (ortalama farkı: 1.058, p=.037) ve 8 . dakikada ölçülen kan laktat düzeyleri arasında (ortalama farkı: 1.425, p=.006) istatiksel olarak anlamlı bir farkl111k bulunmuştur. 
Tablo 7. Dinlenik ve yüksek (\%90) şiddetteki egzersizden sonra 1. dakika, 4. dakika ve 8. dakikada ölçülen kan laktat düzeylerinin (mmol) karşılaştırılması.

\begin{tabular}{cccccc}
\hline Kan laktat düzeyi & $\mathbf{X}$ & S.S. & Sayı & F & p \\
\hline Dinlenik & 2.10 & 1.08 & 12 & & \\
1.Dakika & 11.81 & 3.96 & 12 & 36.697 & $.000^{*}$ \\
4. Dakika & 9.48 & 3.05 & 12 & & \\
8. Dakika & 7.97 & 3.10 & 12 & & \\
\hline
\end{tabular}

Mauchly's testi sonucuna göre, küresellik varsayımı p=.340 olarak bulunmuştur. Tablo 7'de görüldügü gibi dinlenik ve yüksek (\%90) şiddetteki egzersizden sonra 1. dakika, 4. dakika ve 8. dakikada ölçülen kan laktat düzeylerinin karşılaştırılmasında istatiksel olarak anlamlı fark görülmüştür $(\mathrm{F}(3,33)=36.697, \mathrm{p}=.000)$. Bonferroni testi sonuçlarına göre; dinlenik ile egzersizden sonra 1. Dakika (ortalama fark1: $-9.708, \mathrm{p}=.000$ ), 4. dakika (ortalama fark1: $-7.375, \mathrm{p}=.000$ ) ve 8. dakika (ortalama fark1: 5.867, p=.001) ölçülen kan laktat düzeyi arasında; egzersizden sonra 1. dakika ile 4. (ortalama farkı: 2.333, $\mathrm{p}=.041$ ) ve 8 . dakika (ortalama fark1: 3.842, $\mathrm{p}=.026$ ) arasında istatiksel olarak anlamlı düzeyde fark bulunmuştur.

Tablo 8. Düşük (\%40), orta (\%60) ve yüksek (\%90) şiddetteki egzersizden önce ölçülen dinlenik kan laktat düzeylerinin (mmol) karş1laştırılması.

\begin{tabular}{cccccc}
\hline Egzersiz Şiddeti & $\mathbf{X}$ & S.S. & Sayı & F & p \\
\hline Düşük (\%40) & 1.85 & 1.18 & 12 & \multirow{2}{*}{.945} & .404 \\
Orta (\%60) & 1.52 & .589 & 12 & & \\
Yüksek (\%90) & 2.10 & 1.08 & 12 & & \\
\hline
\end{tabular}

Mauchly's testi sonucuna göre, küresellik varsayımı $\mathrm{p}=.061$ olarak bulunmuştur. Tablo 8'de görüldüğü gibi hakemlerin düşük (\%40), orta (\%60) ve yüksek (\%90) şiddetteki egzersizden önce ölçülen dinlenik kan laktat düzeylerinin karşılaştırılmasında istatiksel olarak anlamlı fark görülmemiştir $(\mathrm{F}(2,22)=.945, \mathrm{p}=.404)$.

Tablo 9. Hakemlerin düşük (\%40), orta (\%60), yüksek (\%90) egzersiz şiddeti sırasında ölçülen sezinleme zamanı ve karar verme becerileri ile kan laktat düzeyi arasındaki ilişkisi

\begin{tabular}{ccccccccccc}
\hline & \multicolumn{4}{c}{ Düşük (\%40) şiddet } & \multicolumn{3}{c}{ Orta (\% 60) şiddet } & \multicolumn{3}{c}{ Yüksek (\%90) şiddet } \\
\hline Kan Laktat Düzeyi & 1.dk. & 4.dk. & $\mathbf{8 . d k}$ & 1.dk. & 4.dk. & 8.dk. & 1.dk. & 4.dk. & 8.dk. \\
\hline \multirow{2}{*}{ 6mph } & r & -.393 & -.107 & .030 & -.047 & -.211 & .073 & .367 & $.662^{*}$ & $.741^{* *}$ \\
& $\mathrm{p}$ & .206 & .740 & .927 & .884 & .511 & .821 & .240 & $\mathbf{. 0 1 9}$ & $\mathbf{. 0 0 6}$ \\
$\mathbf{1 2 m p h}$ & $\mathrm{r}$ & -.335 & -.266 & -.103 & .247 & -.328 & -.076 & .338 & .438 & .202 \\
Karar & $\mathrm{p}$ & .287 & .404 & .750 & .440 & .298 & .815 & .282 & .155 & .528 \\
Verme & $\mathrm{r}$ & -.345 & -.570 & $-.577^{*}$ & .046 & .155 & -.034 & -.205 & -.110 & .143 \\
$* \mathrm{p}<0.05$ & $\mathrm{p}$ & .271 & .053 & $\mathbf{. 0 4 9}$ & .888 & .631 & .917 & .523 & .733 & .657 \\
\hline
\end{tabular}


Tablo 9'da gösterildiğinde; \%40 şiddette yapılan egzersizden sonra 8.dakika ölçülen kan laktat düzeyi ile karar verme düzeyi arasında negatif yönde anlamlı ilişki ( $\mathrm{r}=-.577, \mathrm{p}=.049)$ bulunmuştur. Orta (\%60) şiddette yapılan egzersizden sonra 1. dakika, 4. dakika ve 8. dakika ölçülen kan laktat düzeyi ile mutlak hata skoru (6mph, 12mph) ve karar verme düzeyi arasında anlamlı ilişki bulunmamıştır (p>0.05). Yüksek (\%90) şiddette yapılan egzersizden sonra 4. dakika $(\mathrm{r}=.662, \mathrm{p}=.019)$ ve 8. dakikada $(\mathrm{r}=.741$, $\mathrm{p}=.006)$ ölçülen kan laktat düzeyi ile mutlak hata skoru $(6 \mathrm{mph})$ arasında istatiksel olarak pozitif yönde anlamlı ilişki bulmuştur.

\section{TARTIŞMA}

$\mathrm{Bu}$ çalışma, futbol hakemlerinin farklı egzersiz şiddetlerinde (\%40, \%60, \%90) sezinleme zamanı (6mph ve $12 \mathrm{mph}$ ) ve karar verme becerisi ile kan laktat düzeyini incelemek amaciyla yapılmıştır.

Yüksek şiddette yapılan egzersizde laktik asit artarken Ph azalır. Bunun sonucunda ise yorgunluk oluşur. Egzersiz sonrasında laktik asidin uzaklaştırılması için enerji gerekmektedir. Bu enerji daha çok aerobik yolla sağlanır. Maksimal egzersiz sonrasında laktik asidin yarısının uzaklaştırılması için 25 dakikalık dinlenme-toparlanma periyoduna ihtiyaç vardır. Ayrıca laktik asidin \% 95'i 1 saat 15 dakika da uzaklaştırılır (Günay ve ark., 2013). Çalışmanın bulgularına bakıldığında özellikle yüksek şiddetli

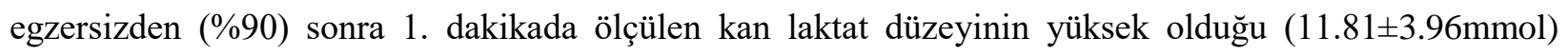
görülmektedir. Düşük, orta ve yüksek şiddetli yapılan egzersizden sonra kan laktat düzeyinde kademeli olarak düşüş gözlenmiştir (Tablo 5, 6, 7). Ishiara ve ark., (2015) maç sırasında futbol hakemlerinin toplam $11.3 \pm 0.6 \mathrm{~km}$ mesafe yaptığını, bunun $1.9 \pm 0.4 \mathrm{~km}$ 'sinin yükssek şiddetli aktivite olduğunu belirtmiştir. Kan laktat değeri $(14.5 \pm 1.0)$ ile yüksek şiddetli aktivite arasında pozitif yönde ilişki bulmuştur. Ayrıca, hakemlerin maç performansının değerlendirilmesinde maç içerisinde kat ettikleri toplam mesafeden ziyade yüksek şiddetli koşu mesafesinin önemli olduğunu göstermiştir. Castillo ve ark., (2018) İspanya 3.ligi maçlarını yöneten 44 ulusal hakem üzerinde yaptıkları çalışmada, hakemlerin maç içerisinde toplam $10,091.12 \pm 794.06 \mathrm{~m}$ mesafe aldığını, bu mesafenin $2901.76 \pm 688.82 \mathrm{~m}$ 'sinin yüksek şiddetli aktivite olduğunu belirtmiştir. Ayrıca maç sonunda hakemlerin kan laktat düzeyinin $7.65 \pm 1.45\left(\mathrm{mmol} \cdot \mathrm{L}^{-1}\right)$ olduğunu bildirmiştir. Yüksek şiddetli aktivite ile kan laktat düzeyleri arasında ilişki olmadığını rapor etmiştir. Castillo ve ark., (2016) en az 6 yıl deneyime sahip, İspanya Ulusal Liglerinde görev yapan 45 hakemin Yo-Yo AT1 sonucunda; kan laktat düzeyini hakem için $8.33 \pm 2.04$ mmol.L ${ }^{-1}$, yardımcı hakem için $7.34 \pm 2.46$ mmol. $\mathrm{L}^{-1}$ olarak bulmuştur. Da Silva ve ark., (2008) resmi maçlarda Brezilyalı hakemlerin ortalama $9155.47 \pm 379 \mathrm{~m}$ mesafe kat ettiklerini, $734.7 \pm 65$ kcal enerji harcadıklarını bildirmiştir. Toplam mesafe ve enerji tüketimi bakımından hakemlerin futbolcularla benzerlik gösterdiğini tespit etmiştir. Castagna ve ark., (2005) Yo-Yo AT1 testi sonrasında kan laktat düzeyi elit hakemler için $8.0 \mathrm{mmol} . \mathrm{L}^{-1}$, orta seviyedeki hakemler için $11.5 \mathrm{mmol} . \mathrm{L}^{-1}$, düşük seviyedeki hakemler için ise 10.5 mmol.L $\mathrm{L}^{-1}$ olarak bulmuştur. Boullosa ve ark., (2012) İspanya bölgesel ve üçüncü lig kadın ve 
erkek futbol hakemlerinin Yo-Yo AT1 testi sonrasında kan laktat düzeyini kadın hakemlerde 8.2 mmol.L${ }^{1}$ erkek hakemlerde 10.5 mmol.L ${ }^{-1}$ olarak rapor etmiştir. Kumar ve ark., (2012) yüksek egzersiz şiddeti ile kan laktat üretimi arasında pozitif ilişki bulmuştur.

Araştırmanın bulguları incelendiğinde; düşük (\%40), orta (\%60) ve yüksek (\%90) egzersiz şiddeti sırasında 6mph ve $12 \mathrm{mph}$ uyarı hızı için ölçülen mutlak hata skorları karşılaştırıldığında, istatiksel olarak anlamlı farklılık bulunamamıştır ( $\mathrm{p}>0.05$ ). (Tablo 2, Tablo 3). Bu araştırmanın bulguları ile paralel olmayan çalışma sonuçlarına bakıldığında; Duncan ve ark., (2013) yüksek şiddetli egzersizlerin, rastlantıya bağı sezinleme zamanını olumsuz yönde etkilediğini göstermiştir. Duncan ve ark., (2014) 8 erkek, 10 kadın üzerinde yapmış olduğu çalışmada fizyolojik uyarılmanın sezinleme zamanı üzerindeki etkinin catastrophe modeli ile açıklanıp açıklanmayacağını araştırmıştır. Yüksek kaygı ve yüksel fizyolojik uyarılmaların olduğu durumlarda, mutlak hata skorlarının yüksek olduğunu bildirmiştir. Bilişsel olarak duyulan kaygının, kalp atım rezervinin \%30, \%50, \%70'inde yapılan egzersizlere göre kalp atım rezervinin \%90’ında yapılan egzersizlerde daha yüksek olduğu görülmüştür. Duncan ve ark., (2013) ve Duncan ve ark., (2014) yaptığı çalışmada örneklem grubu öğrencilerden oluşmuştur. Bu çalışmada ise örneklem grubu düzenli olarak haftada 2 gün antrenman yapan bireylerden seçilmiştir. Sezinleme zamanının farklı egzersiz şiddetlerinden anlamlı düzeyde etkilenmemesi örneklem grubu ile ilgili olabilir. $\mathrm{Bu}$ yorumu destekleyen çalışmalara bakıldığında; Hüttermann ve ark., (2014) yaptığı çalışmada takım sporcuları ile sporcu olmayanların üç farklı egzersiz şiddetinde dikkat performanslarını incelemiştir. Sporcu olanlar, sporcu olmayanlara göre yüksek şiddetli egzersizler sırasında dikkat performanslarını devam ettirmiştir. Sporcu olmayanlar ise bireysel kalp atım sayılarının \%60'ında iken fiziksel egzersiz ile bilişsel performansları ters $U$ göstermiştir. Atletik düzeyin, egzersiz şiddeti ile bilişsel performans arasındaki ilişkide moderator bir etkiye sahip olduğunu bildirmiştir. Lyons ve ark., (2008) yaptığı çalışmada, farklı egzersiz şiddetlerinin deneyimli beyzbol oyuncularının sezinleme zamanı üzerinde istatiksel olarak herhangi bir etkiye sebep olmadığını, sadece orta şiddetli egzersizlerde gelişmiş sezinleme zamanı performansının görüldüğünü bulmuştur.Kashiara ve Nakara (2005) laktat eşiğinde yapılan egzersizlerin bilişsel performas üzerinde olumsuz etki yaratmadığını belirtmiştir. Davrance ve ark., (2015) yüksek egzersiz şiddetinin bilişsel kontrolü etkilemediğini bildirmiştir. Browne ve ark., (2017) yaptıkları sistematik derleme çalışmasında, yüksek fitness düzeyine sahip olmanın, şiddetli egzersizin bilişsel performans üzerindeki yıkıcı etkisini azalttığını göstermiştir. Ayrıca, antrenmanlı bireylerde akut yüksek yoğunluklu egzersizin bilişsel performans üzerindeki etkisinin değerlendirilen spesifik bilişsel alana bağlı olduğunu belirtmiştir. Genel olarak, basit görevler etkilenmezken, karmaşık görevlerdeki sonuçlar belirsiz kalmıştır. Doğruluk, hız ölçümlerine kıyasla yüksek yoğunluklu egzersizden çok az etkilenme eğilimi göstermiştir. Schapschröer ve ark., (2016) akut fiziksel egzersizin sporcuların algısal performansları üzerindeki etkisinin, uyarılan egzersizin ve algısal-bilişsel görevin 
özgüllüğüne bağlı olduğunu rapor etmiştir. Sporcuların sporcu olmayanlara göre akut fiziksel egzersizden daha pozitif etkilendiğini bildirmişsir.

Hakemliğin en önemli yönü karar verme sürecidir. Oyun boyunca bir hakem kısıtlı zamanlar içerisinde doğru kararlar vermek zorundadır (Helsen ve Bultynck, 2004). Yorgunluk bilişsel işlem sürecini etkileyerek hareket kontrol yeteneğini azaltır. $\mathrm{Bu}$ da kararların geç alınmasına sebep olur (Almonroeder ve ark., 2018). Araştırmanın sonucuna bakıldığında; düşük (\%40), orta (\%60) ve yüksek (\%90) şiddetteki egzersiz sırasında ölçülen karar verme becerilerinin karşılaştırılmasında istatiksel olarak anlamlı düzeyde fark görülmüştür ( $\mathrm{p}<0.05)$. İkili karşılaştırılmalarda; düşük $(\% 40)$ ile yüksek $(\% 90)$ şiddetteki egzersizler arasında anlamlı düzeyde farklılık bulunmuştur $(\mathrm{p}<0.05)$. Hakemler, düşük, orta ve yüksek şiddetli egzersizler sırasında kararların sırasıyla, \%80.4, \%76.45, \%72.7’ini doğru bilmiştir. Hakemlerin, yüksek şiddetli egzersiz sırasında verdikleri kararlar, düşük şiddetli egzersiz sırasında verdikleri kararlar ile karşılaştırıldığında, \%7.7 karar verme performansında azalma gözlemlenmiştir (Tablo 4). Yerkes ve Dodson tarafından öne sürülen teoriye göre düşük (uykulu, uyuşuk) ve çok yüksek uyarı düzeylerinde (heyecanlı, tedirgin) performansın olumsuz yönde etkilenir. Orta düzey bir uyarının optimal performans için gereklidir (Papaioannou ve Hackfort, 2014). Performans ile uyarı arasındaki ilişkiyi açıklayan teorilerden bir tanesi de Catastrophe modelidir. Hardy ve Parfitt tarafından geliştirilen teoriye göre fizyolojik uyarı yüksek olduğunda, bilişsel kaygı ve performans arasında negatif ilişki olur. Bilişsel kaygı düşük olduğunda performans ile uyarı arasındaki ilişki Ters U gösterir. Bilişsel kaygı düzeyi yüksek olduğunda ise artan fizyolojik uyarı, atletik performansta ciddi düşüşe sebep olur. Bir başka teori ise, Hanin tarafından öne sürülen bireysel optimal işlevsel bölge (IZOF) teorisidir. Bu teori, optimal uyarının bireysel olarak değiştiğini, bazı sporcuların, çok düşük veya çok yüksek uyarılma düzeylerinde iyi bir performans sergilediğini belirtir (Robbins ve Madrigal, 2016). Bu çalışmanın karar verme becerileri ile ilgili sonuçları, Ters $U$ hipotezi ile Catastrophe modelini desteklemektedir. Gaoua ve ark., (2017) tarafından yapılan çalışma, aşırı sıcak ortamlarda yapılan şiddetli egzersizin karar vermeyi etkileyebilecek fizyolojik ve psikolojik stresi artırdığını göstermektedir. Bu nedenle, oyunun temposuna ayak uydurmak için gerekli olan fiziksel ve aşırı sıcaklıklardan kaynaklanan termal zorlamanın, hakemlerin hızlı ve doğru kararlar vermesini engelleyebileceğini bildirmiş̧tir. Helsen ve Bultynck (2004) yaptıkları çalışmada video eğitimin hakemlerin karar verme becerilerini geliştirmede önemli bir araç olduğunu bildirmiştir. Hakemlerde, karar vermeden hemen önce artan fizyolojik yükün, karar verme sürecine dahil olan bilişsel süreçleri olumsuz yönde etkilediğini bulmuştur. Bir karar öncesi yüksek koşu hızının, karar verme hata olasılığını artırdığını göstermiştir. Mallo ve ark., (2012) hakem ve yardımcı hakemlerin maç sonlarına doğru yanlış karar verme riskinin arttığını belirtmiştir. Catteeuw ve ark., (2010) yaptıkları çalışmada, yorgunluğun hakemlerin off-side kararını etkilemediğini bildirmiştir. Balmer ve ark., (2007) gürültü ile birlikte artan kaygının, hakemlerin kararlarında tutarsızlığa sebep olduğunu 
belirtmiştir. Yapılan bir çalışmada serbest vuruş öncesi hakemin koşu hızının yüksek olmasının, karar verme becerileri ile ilişkili bilişsel süreçler üzerinde olumsuz etki yarattı̆̆ını (Elsworthy ve ark., 2014). Almonroeder ve ark., (2018) sporcular tükenme noktasına yaklaştıklarında yorgunluğun karar verme ile ilgili bilişsel süreçleri etkileyebileceğini belirtmiştir. Smith ve ark., (2016) 15 antrenmanlı denek üzerinde yaptığı araştırmada, 10 dakika süren yüksek şiddetli egzersiz sırasında reaksiyon zamanının yavaşladığını, ihmal ve karar verme hatalarının ise arttığını rapor etmiştir. Whyte ve ark., (2015) yüksek şiddetli egzersizlerin özellikle frontal yönetici fonksiyonda olmak üzere nöro-bilişsel fonksiyonda azalmaya sebep olduğunu bildirmiştir. Labelle ve ark., (2013) orta şiddetteki egzersizlere göre yüksek şiddetli egzersizler sırasında bilişsel performansın (yönetici kontrol) olumsuz etkilendiğini göstermiştir. Rooks ve ark., (2010) düşük şiddetten yüksek şiddetli egzersize doğru serebral oksijenasyonun arttığını ve daha sonra plato oluştuğunu, çok şiddetli ve yorucu egzersizler sırasında ise serebral oksijenasyonun azaldığını belirtmiştir. Mcmorris ve Hale (2012) yüksek şiddetli egzersizlerin katekolamin düzeylerinde artışa sebep olduğunu, bu artışın nöral gürültüyü tetiklediğini bunun da bilişsel performansı olumsuz etkilediğini vurgulamıştır. Yapılan başka bir çalışmada Elsworthy ve ark. (2014) hakemlerin herhangi bir karar öncesi yaptığı egzersiz, solunum eşiğinin üzerinde olursa, serebral kan akımındaki değişikliklerden dolayı, karar verme becerilerinin olumsuz etkilenebileceğini göstermiştir.

\section{SONUÇ, SINIRLIKLAR VE ÖNERILER}

Lambourne ve Tomporowski (2010) egzersize bağlı uyarının bilişsel performans üzerine olan etkisini incelediği meta-analiz çalışmasında, egzersiz ile bilişsel performans arasında kompleks ilişki olduğunu, bilişsel performansın gelişmesi veya bozulmasının, egzersiz şiddetine, egzersiz çeşidine ve ölçülecek olan bilişsel görevin tipine bağlı olduğunu belirtmiştir. Sonuç olarak; özellikle hakemlerin yüksek şiddetteki egzersizlerden sonra kan laktat düzeyi yüksek bulunmuştur. Yüksek şiddetteki egzersizlerde karar verme düzeyi anlamlı düzeyde bozulurken, sezinleme zamanı da anlamlı olmamasına rağmen olumsuz etkilenmiştir. Bunun sebebi ise kan laktat düzeylerindeki artıştan kaynaklanmış olabilir. Farklı egzersiz şiddetlerinin karar verme becerisi üzerinde anlamlı, sezinleme zamanın üzerinde ise anlamlı olmamasına rağmen olumsuz etkiye sahip olmasının sebebi ise Lambounre ve Tomporowski (2010) belirttiği gibi ölçülen bilişsel performans görevinin tipi ile de ilişkili olabilir. Hakemlerin, sezinleme zamanı ve karar verme becerilerinin egzersiz sırasında ölçümü yapılırken, aynı zamanda kan laktat düzeylerinin belirlenmesinin hakemlerin yorgunluk ve algısal bilişsel becerileri arasındaki ilişkiyi açıklamak için net bilgi sağlayabileceği düşünülmektedir. $\mathrm{Bu}$ da çalışmanın sınırlıkları arasında değerlendirilebilir.

$\mathrm{Bu}$ çalışmada hakemlerin laboratuvar ortamında farklı şiddetteki egzersizler sırasında sezinleme zamanı ve karar verme becerileri ölçüldü. Oysa gerçek futbol müsabakasında hakemler artan fizyolojik 
yükün yanı sıra birçok faktör (seyirci veya oyuncu baskısı) ile karşı karşıya kalmaktadır. Bu çalışmada bu gibi faktörler dikkate alınmadı. Bir sonraki çalışmalarda, hakemlerin resmi maçlar sırasında maç performansının (egzersiz şiddeti, karar verme becerileri) değerlendirilmesi önerilmektedir. Bu çalışmada egzersiz şiddeti Karvonen yöntemi ile belirlenmiştir. Egzersiz şiddeti belirlenirken hakemlerin maksimal güç çıktıları veya $\mathrm{MaxVO}_{2}$ kapasiteleri de dikkate alınabilirdi. İleriki çalışmalarda cinsiyet ve deneyim faktörü de dikkate alınarak elit hakem ve yardımcı hakemlerde, farklı egzersiz şiddetlerinin üst düzey çeşitli algısal-bilişsel özellikler üzerine etkisinin incelenmesi önerilmektedir. Hakemlerin artan egzersiz şiddetinde ve kan laktat düzeyinde algısal özelliklerini koruyup düzgün kararlar verebilmesi için antrenmanlarda algısal ve motorsal özelliklerinin geliştirilmesinin önemli olduğu düşünülmektedir.

\section{KAYNAKLAR}

Alaei, F. (2015). Effects of exercise intensity and stimulus speed on coincidence anticipation timing with respect to gender in adolescent badminton players. Doctor of Philosophy dissertation, Middle East Technical University. Ankara.

Almonroeder, T. G., Tighe, S. M., Miller, T. M., Lanning, C. R. (2018). The influence of fatigue on decision-making in athletes: a systematic review. Sports Biomechanics, 14, 1-14.

Balmer, N.J., Nevill, A.M., Lane, A.M., Ward, P., Williams, M.A., Fairclough, S.A. (2007) Influence of crowd noise in soccer on soccer refereeing consistency. Journal of Sport Behavior, 30(2), 130-145.

Boullosa, D.A, Abreu, L., Tuimil, J.L, Leicht, A.S. (2012). Impact of a soccer match on the cardiac autonomic control of referees. European Journal of Applied Physiology, 112(6), 2233-2242.

Browne, S. E., Flynn, M. J., O’Neill, B. V., Howatson, G., Bell, P. G., Haskell-Ramsay, C. F. (2017). Effects of acute highintensity exercise on cognitive performance in trained individuals: A systematic review. In Progress in Brain Research, 234, 161-187.

Byun, K., Hyodo, K., Suwabe, K., Ochi, G., Sakairi, Y., Kato, M., Dan, I., Soya, H. (2014). Positive effect of acute mild exercise on executive function via arousal-related prefrontal activations: an fNIRS study. Neuroimage, 98, 336-345.

Castagna, C., Abt, G., \& D'ottavio, S. (2007). Physiological aspects of soccer refereeing performance and training. Sports Medicine, 37(7), 625-646.

Castagna, C., Abt, G., D’Ottavio, S. (2005). Competitive level differences in yo-yo intermittent recovery and 12 min run test performance in soccer referees. Journal of Strength and Conditioning Research, 19(4), 805-809.

Castillo, D., Camara, J., Lozano, D., Berzosa, C., Yanci, J. (2018). The association between physical performance and match-play activities of field and assistants soccer referees. Research in Sports Medicine, 20, 1-15.

Catteeuw, P., Gilis, B., Wagemans, J., \& Helsen, W. (2010). Offside decision making of assistant referees in the English Premier League: Impact of physical and perceptual-cognitive factors on match performance. Journal of Sports Sciences, 28(5), 471-481.

Ceylan, H. I., Saygin, O. (2018). Acute effect of various exercise intensities on cognitive performance. European Journal of Physical Education and Sport Science, 4(2), 157-172.

Choi, Y., Roh, J. (2018). Activity profile and physiological responses of Korean amateur football referees during matches. Journal of Physical Therapy Science, 30(2), 351-354.

Da Silva, A. I., Fernandes, L. C., Fernandez, R. (2008). Energy expenditure and intensity of physical activity in soccer referees during match-play. Journal of Sports Science \& Medicine, 7(3), 327-334.

Davranche, K., Brisswalter, J., Radel, R. (2015). Where are the limits of the effects of exercise intensity on cognitive control? $J$ Sport Health Sci, 4, 56-63.

D'Ottavio, S., Castagna, C. (2001). Physiological load imposed on elite soccer referees during actual match play. Journal of Sports Medicine and Physical Fitness, 41(1), 27-32.

Duncan, M., Smith, M., Lyons, M. (2013). The Effect of exercise intensity on coincidence anticipation performance at different stimulus speeds. European Journal of Sport Science, 13(5), 559-566.

Duncan, M.J., Smith, M., Bryant, E., Eyre, E., Cook, K., Hankey, J., Tallis, J., Clarke, N., Jones, M.V. (2014). Effects of increasing and decreasing physiological arousal on anticipation timing performance during competition and practice. European Journal of Sport Science, 16(1), 27-35.

Ekmekçi, R. (2011). İyi bir hakemin özellikleri. Pamukkale Journal of Sport Sciences, 2(1), 1-5.

Elsworthy, N., Burke, D., \& Dascombe, J. B. (2014). Factors relating to the decision-making performance of Australian football officials. International Journal of Performance Analysis in Sport, 14(2), 401-410. 
Aslan, K., Saygın, Ö. ve Ceylan, H.İ. (2018). Futbol hakemlerinin farklı egzersiz şiddetlerinde sezinleme zamanı, kan laktat düzeyi ve karar verme becerilerinin incelenmesi. CBÜ Beden Ĕ̈itimi ve Spor Bilimleri Dergisi, 13(2), $260-276$.

Ferguson, B. (2014). ACSM's guidelines for exercise testing and prescription 9th Ed. The Journal of the Canadian Chiropractic Association, 58(3), 328.

Gaoua, N., de Oliveira, R. F., \& Hunter, S. (2017). Perception, action, and cognition of football referees in extreme temperatures: impact on decision performance. Frontiers in Psychology, 8, 1479. doi: 10.3389/fpsyg.2017.01479.

Günay, M., Tamer, K., Cicioğlu, İ. (2013). Spor fizyolojisi ve performans ölçümü. Ankara: Gazi Kitapevi.

Helsen, W., Bultynck, J.B. (2004) Physical and perceptualcognitive demands of top-class refereeing in association football, Journal of Sports Sciences, 22(2), 179-189.

Hüttermann, S., Memmert, D. (2014). Does the inverted-U function disappear in expert athletes? An analysis of the attentional behaviour under physical exercise of athletes and non-athletes. Physiol Behav, 131, 87-92.

Ishihara, Y., Naito, H., Ozaki, H., Yoshimura, M. (2015). Aerobic fitness relation to match performance of japanese soccer referees. Football Science, 12, 91-97.

Jarvis, M., (2006). Sport psychology: a student's handbook. New York: Routledge.

Karvonen, M. J., Kentala, E., Mustala, O. (1957). The effects of training heart rate: a longitudinal study. Annales Medicinae Experimentalis et Biologiae Fenniae, 35, 307-315.

Kashihara, K., Nakahara, Y. (2005). Short-term effect of physical exercise at lactate threshold on choice reaction time. Perceptual and Motor Skills, 100, 275-291.

Kittel, A., Elsworthy, N., \& Spittle, M. (2018). Incorporating perceptual decision-making training into high-intensity interval training for Australian football umpires. Journal of Sports Sciences, 1-7. doi:10.1080/02640414.2018.1480257.

Krustrup, P., Helsen, W., Randers, M. B., Christensen, J. F., MacDonald, C., Rebelo, A. N., Bangsbo, J. (2009). Activity profile and physical demands of football referees and assistant referees in international games. Journal of Sports Sciences, 27(11), 1167-1176.

Krustrup, P., Mohr, M., Bangsbo, J. (2002). Activity profile and physiological demands of top-class soccer assistant refereeing in relation to training status. Journal of Sports Sciences, 20(11), 861-871.

Kumar, A., Kumar, R., \& Kumar, R. (2012). Blood lactate response to different workload patterns in female weight lifters. Journal of Exercise Science and Physiotherapy, 8(2), 87-92.

Labelle, V., Bosquet, L., Mekary, S., \& Bherer, L. (2013). Decline in executive control during acute bouts of exercise as a function of exercise intensity and fitness level. Brain and Cognition, 81(1), 10-17.

Lambourne, K., Tomporowski, P. (2010). The effect of exercise-1nduced arousal on cognitive task performance: a metaregression analysis. Brain Research, 1341, 12-24.

Lyons, M., Al-Nakeeb, Y., Nevill, A., (2008). Post-exercise coincidence anticipation in expert and novice gaelic games players: the effects of exercise intensity. European Journal of Sport Science, 8(4), 205-216.

Mallo, J., Frutos, P. G., Juárez, D., \& Navarro, E. (2012). Effect of positioning on the accuracy of decision making of association football top-class referees and assistant referees during competitive matches. Journal of Sports Sciences, 30(13), 14371445 .

McMorris, T., \& Hale, B. J. (2012). Differential effects of differing intensities of acute exercise on speed and accuracy of cognition: a meta-analytical investigation. Brain and Cognition, 80(3), 338-351.

McMorris, T., \& Hale, B. J. (2015). Is there an acute exercise-induced physiological/biochemical threshold which triggers increased speed of cognitive functioning? A meta-analytic investigation. Journal of Sport and Health Science, 4(1), 4-13.

North, J. S., Hope, E., \& Williams, A. M. (2016). The relative importance of different perceptual-cognitive skills during anticipation. Human Movement Science, 49, 170-177.

Papaioannou, A. G., Hackfort, D. (2014). Routledge companion to sport and exercise psychology: global perspectives and fundamentals concepts. London and Newyork: Routledge.

Piras, A., Lobietti, R., \& Squatrito, S. (2014). Response time, visual search strategy, and anticipatory skills in volleyball players. Journal of Ophthalmology. http://dx.doi.org/10.1155/2014/189268.

Riiser, A., Pettersen, S. A., Andersen, V., Saeterbakken, A. H., Froyd, C., Ylvisaker, E., Moe, V. F. (2017). Accelerations and high intensity running in field and assistant football referees during match play. Science and Medicine in Football, 1(3), 280-287.

Riquelme, D. (2015). The effects of moderate-intensity aerobic exercise on cognition and arousal in extrovert and introvert personality types. Doctor of Philosophy dissertation. Faculty of the University of Miami, Florida.

Robbins, J. E., Madrigal, L. (2016). Sport, exercise, and performance psychology: bridging theory and application. New York: Springer Publishing Company.

Rooks, C. R., Thom, N. J., McCully, K. K., \& Dishman, R. K. (2010). Effects of incremental exercise on cerebral oxygenation measured by near-infrared spectroscopy: A systematic review. Progress in Neurobiology, 92(2), 134-150.

Schapschröer, M., Lemez, S., Baker, J., \& Schorer, J. (2016). Physical load affects perceptual-cognitive performance of skilled athletes: A systematic review. Sports Medicine-Open, 2(1), 37. doi: 10.1186/s40798-016-0061-0.

Schenk, K., Bizzini, M., \& Gatterer, H. (2018). Exercise physiology and nutritional perspectives of elite soccer refereeing. Scandinavian Journal of Medicine \& Science in Sports, 28(3), 782-793.

Sors, F., Murgia, M., Santoro, I., Prpic, V., Galmonte, A., \& Agostini, T. (2017). The contribution of early auditory and visual information to the discrimination of shot power in ball sports. Psychology of Sport and Exercise, 31, 44-51.

Söğüt, M., Ak, E., Koçak, S. (2009). 8-10 Yaş grubu tenis oyuncularının sezinleme zamanı. Hacettepe Spor Bilimleri Dergisi, 20(1), 1-5.

Smith, M., Tallis, J., Miller, A., Clarke, N. D., Guimaraes-Ferreira, L., Duncan, M. J. (2016). The effect of exercise intensity on cognitive performance during short duration treadmill running. Journal of Human Kinetics, 51(1), $27-35$. 
Aslan, K., Saygın, Ö. ve Ceylan, H.İ. (2018). Futbol hakemlerinin farklı egzersiz şiddetlerinde sezinleme zamanı, kan laktat düzeyi ve karar verme becerilerinin incelenmesi. CBÜ Beden Eğitimi ve Spor Bilimleri Dergisi, 13(2), $260-276$.

Spitz, J., Put, K., Wagemans, J., Williams, A. M., \& Helsen, W. F. (2018). The role of domain-generic and domain-specific perceptual-cognitive skills in association football referees. Psychology of Sport and Exercise, 34, 47-56.

Tekus, E., Kaj, M., Szabo, E., Szenasi, N., Kerepesi, I., Figler, M., et al. (2012). Comparison of blood and saliva lactate level after maximum intensity exercise. Acta Biologica Hungarica, 63(1), 89-98.

Weston, M. (2015). Match performances of soccer referees: the role of sports science. Movement \& Sport Sciences-Science \& Motricite, 87, 113-117.

Weston, M., Drust, B. and Gregson, W. (2011). Intensities of exercise during matchplay in FA Premier League referees and players. Journal of Sports Sciences, 29(5), 527-532.

Weston, M., Drust, B., Atkinson, G., \& Gregson, W. (2011). Variability of soccer referees' match performances. International Journal of Sports Medicine, 32(3), 190-194.

Whyte, E. F., Gibbons, N., Kerr, G., Moran, K. A. (2015). Effect of a high-intensity 1ntermittent-exercise protocol on neurocognitive function in healthy adults: 1mplications for return-to-play management after sport-related concussion. Journal of Sport Rehabilitation, 24(4),1-5. http://dx.doi.org/10.1123/jsr.2014-0201.

Williams, A., Davids, K., \& Williams, J. (2000). Visual perception and action in sport. New York: Routledge. 